\title{
LA INCULTURACIÓN DE LA LITURGIA EN LA CULTURA QUECHUA
}

\author{
Enculturation of Liturgy in Quechua Culture \\ Jorge Huanca Larota, OFM \\ Luis Alberto Nahuelanca Muñoz, OFM²
}

\section{Resumen}

La inculturación es una de las herramientas importantes que tiene la Iglesia para encarnar el Evangelio, la fe, la pastoral y la liturgia; asimismo, penetrar el mensaje de Cristo en una determinada cultura autóctona, invitando a crecer según todos sus valores propios, en cuanto son conciliables con el Evangelio. Así, han considerado los obispos teólogos y otros agentes pastorales en diversas asambleas, como la Conferencia Episcopal Latinoamericana. Sobre el tema afianza los documentos de Santo Domingo, Aparecida, recientemente los documentos del papa Francisco, Evangelii gaudium y en Querida Amazonía. En ese entender, para la Iglesia latinoamericana y caribeña, la inculturación de la liturgia constituye un gran desafío que hay que afrontar, a la vez, es una realidad nunca acabada, porque los cambios culturales dificultan la transmisión de la fe, esto urge la necesidad de la inculturación de la fe, por tanto, la liturgia. Por su parte, el papa Francisco hace notar que en este campo no se ha avanzado suficientemente. Esta preocupación nos ha motivado a fortalecer la inculturación de la liturgia en la cultura quechua, tomando algunos signos y símbolos propios en la celebración del misterio de Cristo, puesto que esta cultura es viva, rica y dinámica. Por otra parte, este proceso debe hacerse por el camino de diálogo, para que nuestras celebraciones litúrgicas tengan rostro y corazón andino, como parte de la renovación de la Iglesia local. Para ello, haremos uso del método ver, juzgar y actuar, pues la inculturación es uno de los medios que nos ayuda a transmitir el mensaje de Cristo presente y actuante en el corazón de la cultura quechua.

Palabras clave: Liturgia; Cultura; Inculturación; Cultura quechua; Ágape, Hurk’a; Música; Canto.

1 Vinculado a la fraternidad San Antonio de Padua - La Recoleta - Cusco, Perú. Pertenece a la provincia Franciscana de los XII Apóstoles del Perú. Realizó sus estudios en el Instituto de Estudios Teológicos "Juan XXIII" ISET - Lima, Perú; CEBITEPAL - Bogotá y Universidad Pontificia Bolivariana - Medellín, Colombia. Correo electrónico: huancalarota7@ gmail.com.

2 Doctor en Misionología. Profesor del Instituto de Teología de la Universidad Católica de la Santísima Concepción, Chile. Correo electrónico: nahuelanca@gmail.com 


\section{Abstract}

Enculturation is one of the most significant instruments that Church has to embody the Gospel, faith, pastoral, and liturgy; as well as to deliver the Christian message to some native cultures by inviting them to preserve their traditional values if they can be reconciled with the Gospel. This idea has been encouraged by bishops, theologians, and pastoral agents in different settings, such as the Episcopal Conference of Latin America. In this regard, some relevant writings are the Aparecida and Santo Domingo Documents, and the recently published Evangelii Gaudium and Querida Amazonia, by Pope Francis. For the Church of Latin America and the Caribbean, enculturation of liturgy is a never-ending reality and poses considerable challenges because cultural changes hinder the transmission of faith. Thus, Pope Francis highlights that there has not been enough progress in this respect. On the one hand, this concern has motivated us to strengthen enculturation of liturgy in the Quechua Culture, preserving some of their signs and symbols in the celebration of the mystery of Christ. On the other hand, this process should be undertaken through the path of dialogue to provide our liturgical celebrations with Andean features as part of the renewal of the local Church. Therefore, the article follows the see-judge-act method of analysis, since enculturation is one of the means that helps with the transmission of the present and acting Christian message among the Quechua Culture.

Keywords: Liturgy; Culture; Enculturation; Quechua Culture; Agape; Hurk’a; Music; Singing.

\section{Introducción}

Este artículo es un aporte que busca ofrecer elementos sobre la inculturación de la liturgia de la Iglesia en la cultura quechua, en la que se celebra el misterio de Cristo hace más de quinientos ańos. En efecto, la Iglesia desde el Concilio Vaticano II ha tomado interés en inculturar la liturgia en las culturas indígenas u originarias según las necesidades de los lugares de misión y de la época, respetando el genio y las cualidades peculiares de las distintas razas y pueblos, por lo que se espera que la inculturación de la liturgia en esta cultura continúe por el camino de la escucha y el diálogo con las personas, realidades e historias de su territorio, sin despreciar nada de lo bueno que ya existe, sino recogiendo y llevando a la plenitud la luz del Evangelio (Francisco, 2020, n. 66).

El poblador de la cultura quechua mayormente se autodefine como cristiano, y así también lo califican quienes observan desde fuera; sin embargo, sus modos de ser cristiano y de vivir como católicos son diferentes, porque los expresa desde su espacio sociocultural y religioso. Esta vivencia propia nos lleva a preguntarnos qué elementos propios de la cultura quechua pueden ser inculturados en la celebración litúrgica de la Iglesia, puesto que esta cultura posee muchos elementos propios, como la fe, la sabiduría ancestral, el canto, la música, los ritos, los gestos, las danzas, los símbolos, los colores, la lengua vernácula, el quechua, de donde proviene el nombre de esta cultura, y su piedad popular.

La Iglesia, en su ejercicio pastoral, ha tenido siempre un gran aprecio a los pueblos indígenas u originarios, para ello hoy se requiere fortalecer el trabajo de los misioneros, agentes pastorales, catequistas, animadores de fe andina, puesto que son sujetos de la inculturación del Evangelio, de la fe y en nuestro caso de la liturgia; en un sentido amplio, la Iglesia andina es el sujeto de la inculturación. 
La liturgia de la Iglesia debe llevar adelante y configurarla en dirección a las necesidades pastorales de un culto vivencial. En tal sentido, "la liturgia es el centro de la vida cristiana, a la vez es la pieza nuclear de la vida y de la misión de la Iglesia. La Iglesia celebra la liturgia para glorificación de Dios y santificación de los hombres" (Augustin \& Koch, 2013, p. 11). Asimismo, "la liturgia es la cumbre a la cual tiende la actividad de la Iglesia y al mismo tiempo fuente de donde mana toda su fuerza" (Pablo, 1963, n. 10), en especial, la eucaristía es la fuente y cima de toda la vida cristiana.

Si bien es cierto la inculturación se desarrolló después del Concilio Vaticano II, es un tema antiguo en la Iglesia. Este es un proceso dinámico de aproximación al mundo cultural del otro, es un canal por el cual las aguas del Evangelio pueden regar y fecundar el terreno cultural de los diversos pueblos y grupos sociales. No obstante, "la inculturación es un camino que permite una íntima transformación de los auténticos valores culturales mediante su integración en el cristianismo" (Juan Pablo II, 1990, n. 52). Asimismo, es instrumento que asiente vivir la proximidad sociocultural en analogía con la encarnación de Jesús de Nazaret; un instrumento que permite una presencia respetuosa frente a la alteridad, crítica frente al pecado y solidaridad en el sufrimiento.

La cultura abarca la globalidad de la vida de un determinado grupo étnico o social. Sobre el tema existen diversas definiciones, cada ciencia ha dado su propio aporte, lo importante es que se complementan y se enriquecen. En este entender, "la cultura es aquel todo complejo que incluye el conocimiento, las creencias, el arte, la moral, el derecho, las costumbres y cualquiera otro hábito y capacidades adquiridos por el hombre en cuanto miembro de la sociedad" (El Antropólogo Principiante, s. f.); asimismo, la cultura abarca la sociología y etnología. En este sentido, es "todo aquello por el cual el hombre refina y desarrolla las múltiples capacidades de su espíritu y de su cuerpo; [...] a fin que ellas sirvan al progreso de un gran número e incluso de todo el género humano" (Cardenal, 2004, p. 43). Por otro lado, como afirma el papa Francisco (2013, n. 115), la cultura es un patrimonio de los pueblos, de modo que la noción de cultura es una valiosa herramienta para entender las diversas expresiones de la vida que se dan en el pueblo y se manifiesta en el estilo de vida que tiene una sociedad determinada, el modo propio que tienen sus miembros de relacionarse entre sí, con las demás criaturas y con Dios. De modo que la fe que se encarna en las culturas, "enfoca todas las dimensiones — aun estructurales - de su vida y convivencia, en las cuales se ha de encarnar el Evangelio, a saber, las dimensiones religiosas, cultural en sentido restringido social, político, económico, etc." (Scannone, 2017, p. 46).

La cultura quechua es una cultura viva en sus tradiciones, costumbres y piedad popular, rica en sus manifestaciones sociopolítica, cultural, económica y religiosa, y dinámica, porque se mantiene en constante transmisión a las generaciones venideras. También se caracteriza por su diversidad de flora y fauna, maravilla de la mano de Dios. En la vida social, están organizados en kawri (familia), ayllu (comunidad), llaqta o marka (pueblo) y suyo (nación). Su sistema laboral está organizado en tres formas: la mita (trabajo en bien de la comunidad, pueblo y nación), el ayni (intercambio de trabajo entre grupos de familia) y la minka (trabajo que se practica en ayuda mutua). El código ético, muy valioso en la vida cotidiana de esta cultura, es el saludo diario: ama qella (no seas ocioso), ama suwa (no seas ladrón), ama llulla (no seas mentiroso) y la respuesta hinallataq qampas (igualmente tú).

Dado el interés por el tema de la inculturación, consideramos presentar el trabajo en dos puntos con sus respectivos subtítulos. Lo primero, la liturgia y la cultura: diálogo de inculturación, y lo segundo, la 
cultura quechua, puesto que esta cultura conoce a Dios, llamándolo Papito, en quechua: Tayta, Taytacha, con una modalidad radicalmente afectuosa, humilde y respetuosa.

\section{Liturgia y cultura: diálogo de inculturación}

El papa Francisco en Evangelii gaudium afirma: "Es imperiosa la necesidad de evangelizar las culturas para inculturar el Evangelio" (Francisco, 2013, n. 69). Por consiguiente, "en la inculturación, la Iglesia introduce a los pueblos con sus culturas en su misma comunidad, porque toda cultura propone valores y formas positivas que pueden enriquecer la manera de anunciar, concebir y vivir el Evangelio" (n. 116).

En tal sentido, la inculturación de la fe, el Evangelio, en nuestro caso la liturgia, es la integración de la experiencia de una iglesia local en la cultura del pueblo en que mora, de tal forma que esa experiencia no solo se expresa conforme a lo específico de dicha cultura, sino que también llega a convertirse en una fuerza que anima, orienta y renueva, creando en ella una nueva unidad de comunión enriquecedora para ella misma y para la Iglesia universal (Piedra, 2013, p. 50). Este proceso ha tomado fuerza después del Concilio Vaticano II, así la constitución Sacrosanctum Concilium afirma:

Este Sacrosanto Concilio se propone acrecentar de día en día entre los fieles la vida cristiana, adaptar mejor a las necesidades de nuestro tiempo las instituciones que están sujetas a cambio, promoviendo todo aquello que pueda contribuir a la unión de cuanto creen en Jesucristo y fortalecer cuanto sirve a todos los hombres al seno de la Iglesia. (Pablo, 1963, n. 1).

Sacrosanctum Concilium ha motivado a las conferencias episcopales, a los obispos en sus respectivas iglesias particulares, a los teólogos, a los liturgistas, a los agentes pastorales y a los catequistas a reflexionar sobre la liturgia y su inculturación en las culturas autóctonas, respetando y promoviendo el genio y las cualidades peculiares de las distintas razas, pueblos (Pablo, 1963, n. 37-38), grupos, regiones, en especial, en las misiones, asumiendo la traducción de los libros litúrgicos a las lenguas vernáculas, el uso de la música, el canto y las artes sagradas (n. 29). A la vez, la Iglesia ha elaborado unas disposiciones orientativas con las que promueve un debido proceso de inculturación de la liturgia, y sí evitar todo tipo de abusos y exageraciones que puede cometerse el proceso; de estas mencionamos tres: Musicam sacram (1967), Varietates legitimae (1994) y Liturgiam authenticam (2001).

El papa Francisco, igualmente, en sus exhortaciones apostólicas ha invitado a la Iglesia a seguir profundizando en la inculturación del Evangelio, la fe, la liturgia y la pastoral (Francisco, 2013, n. 68-70; 2020, n. 66-90, 81-84).

\section{Liturgia}

Cuando se habla de la liturgia, nos encontramos con un tema rico en su dimensión teológica y pastoral en la vida de la Iglesia. "La liturgia es la obra por excelencia de Dios, sin dejar de ser la acción más profundamente 
humana. Es el ámbito más significativo del encuentro y el diálogo entre Dios y el hombre, en y por la comunidad" (Borobio, 2003, p. 17), pues, en Sacrosanctum Concilium (Pablo, 1963), encontramos una serie de principios conceptuales y celebrativos.

La palabra liturgia etimológicamente proviene del griego clásico, leitourgia, que traducida literalmente significa "servicio hecho al pueblo" o "servicio directamente prestado para el bien común". A la vez, esta palabra está compuesta por vocablos como leito (popular, del pueblo) y ergon (obra) (Augé, 1997, p. 13).

Sacrosanctum Concilium (Pablo, 1963, n. 14) ofrece conceptos teológicos y pastorales. Asimismo, brinda una mayor comprensión para una participación activa de los fieles del misterio celebrado, pues la liturgia es la fuente primera de la que los fieles han de beber el espíritu verdaderamente cristiano.

La liturgia es la celebración del misterio pascual de Cristo (Pablo, 1963, n. 5), en que "se hace realidad la salvación del hombre en la muerte y resurrección de Jesús y se continúa ahora, se actualiza y se ofrece en la celebración litúrgica de la Iglesia" (Molina, 2015, p. 89). A la vez, Jesús retoma la promesa de Dios de estar junto a y con su pueblo. En tal sentido, "la muerte de Jesús se convierte en nuevo éxodo y nueva Pascua, en tránsito de la muerte a la vida, en liberación de la más profunda cautividad del ser humano al inevitable de la muerte" (Kasper, 2015, pp. 29-30). En consecuencia, en palabras de Basurko (2006): "El misterio pascual encierra en una expresión sintética el núcleo esencial de nuestra fe" (p. 460); también es "la redención de Cristo vista bajo todos aspectos, con todas sus raíces y derivaciones, con todos sus armónicos bíblicos, litúrgicos, éticos y hasta místicos” (p. 462).

Así pues, Pablo (1963, n. 7) afirma: "La liturgia es ejercicio del sacerdocio de Jesucristo". Sobre el tema indica Mediator Dei (Pío XII, 1947): "el sacerdocio de Jesucristo se mantiene siempre activo en la sucesión de los tiempos, ya que la liturgia no es sino el ejercicio de este sacerdocio" (n. 32). Después, Pablo (1963) recoge esta definición y la enriquece:

La liturgia se considera como el ejercicio de la función sacerdotal de Jesucristo. En ella los signos sensibles significan y, cada uno a su manera, realizan la santificación del hombre, y así el Cuerpo Místico de Jesucristo, es decir, la Cabeza y sus miembros, ejercen el culto público íntegro. (n. 7).

Al respecto, Goñi (2009) señala que en el sacerdocio de Cristo hay dos aspectos que comportan: "El culto (la ofrenda de su vida) y la mediación (su intercesión entre Dios y los hombres), es este último el que entra de modo particular en juego en la celebración” (p. 71). En tal sentido, el primer aspecto compete a todos los bautizados a ofrecer sus vidas como ofrenda agradable al Padre, en tanto, el segundo aspecto

quedaba reservado exclusivamente a Cristo. Esta dimensión se prolongó en el tiempo por los ministros ordenados, dado que representa sacramentalmente a Cristo. No obstante, como también la asamblea reunida queda constituida como cuerpo de Cristo, unida a su cabeza, esto es, al sacerdote ordenado, puede ejercer la dimensión mediadora de Cristo sacerdote. (p. 72)

En efecto, "lo mismo que su Cabeza divina, también la Iglesia asiste continuamente a sus hijos, les ayuda y les exhorta a la santidad, para que, adornados con esta dignidad sobrenatural, puedan un día volver al Padre, que está en los cielos" (Pío XII, 1947, n. 32). 
Otra de las dimensiones que Pío XII (1947) ofrece es la dimensión pneumatológica de la liturgia. "Desde entonces, la Iglesia nunca ha dejado de reunirse para celebrar el misterio pascual... para alabar su gloria, por la fuerza del Espíritu Santo" (n. 6). Al respecto, el Catecismo de la Iglesia Católica (1993) afirma: "En la liturgia, el Espíritu Santo es el pedagogo de la fe del pueblo de Dios, el artífice de las obras maestras que son sacramentos de la Nueva Alianza... la liturgia viene a ser la obra común del Espíritu Santo y de la Iglesia" (n. 1091). Por eso, "el Espíritu Santo es el alma de la Iglesia, el que anima e impulsa el crecimiento personal en Cristo y la extensión misionera del reino de Cristo... y el que da sentido y eficacia a la liturgia y los sacramentos de la Iglesia" (Borobio, 2003, p. 43). Por tanto, las tres dimensiones temporales de la liturgia, como la rememoración, actualización y anticipación, son obras del Espíritu Santo. A través de él, Jesús está presente permanentemente en el mundo, en la historia y, en especial, en la Iglesia y la vida de los cristianos (Kasper, 2015, p. 34).

Por otro lado, también encontramos la dimensión escatológica de la liturgia en la constitución Sacrosanctum Concilium: "En la Liturgia terrena preguntamos y tomamos parte en aquella Liturgia celestial, que se celebra en la santa ciudad Jerusalén [...] hasta que se manifieste Él nuestra vida, y nosotros manifestamos también gloriosos con Él” (Pablo, 1963, n.o 8). Así, la Iglesia en la celebración de la liturgia, pone la realidad entera a la luz del resplandor de la transfiguración escatológica, momento en que Dios será todo en todos (Kasper, 2015, p. 83). Al respecto, Molina (2015) señala: “esto crea la comunión entre la Iglesia celeste y la terrena. Al mismo tiempo se renueva la esperanza en lo definitivo que solo llegará con Cristo" (p. 93).

Sacrosanctum Concilium afirma la dimensión eclesial de la liturgia, "pues del costado de Cristo dormido en la cruz nació el sacramento admirable de la Iglesia entera" (Pablo, 1963, n. 5). De ahí que "la liturgia como signo da la imagen más verdadera y plena de la Iglesia, comunidad de culto reunida en torno al mismo altar, bajo la presencia de sus legítimos pastores" (Molina, 2015, p. 91). En este entender, la Iglesia es la comunidad que celebra y festeja cada pequeńa victoria, cada paso adelante en la evangelización. Esta tarea de evangelización gozosa se vuelve belleza en la liturgia en medio de la exigencia diaria de extender el bien. Por otra parte, la Iglesia evangeliza y se evangeliza a sí misma con la belleza de la liturgia, la cual también es celebración de la actividad evangelizadora y fuente de una renovación de impulso donativo (Francisco, 2013, n. 24). Así pues, la evangelización culmina en la liturgia, de la liturgia nace y saca su fuerza la misión (Pablo, 1963, n. 10).

\section{Cultura}

Existen diversidad de significados frente al concepto de cultura; cada disciplina ha dado su aporte desde su campo de estudio. Pero, eso sí, con el aporte de ellas se complementa y se enriquece el concepto. Por otra parte, en sentido amplio, la cultura viene a ser todo aquello por lo cual el hombre refina y desarrolla las múltiples capacidades de su cuerpo y de su espíritu en el pueblo y contexto; tal como la afirman Martínez et al. (2016):

La cultura es uno de los pivotes del desarrollo de los pueblos, teniendo en cuenta que fortalece las libertades fundamentales, mejora la infraestructura cultural, económica y remunerativamente reafirma las 
actitudes y aptitudes y el comportamiento social; robustece la participación política y ciudadana, vigoriza la solidaridad social y cooperación; y refina la formación en valores y fortalece la re-memorización de la herencia histórica. (p. 14).

Así pues, el concepto de cultura tiene numerosas acepciones y aportes de las diversas ciencias sociales, como la antropología y la sociología. En tal sentido, "el concepto de cultura forma parte del eje central de los principales de la historia de la antropología" (Fernández, 2009, p. 3). Desde esta perspectiva, el concepto de cultura desde la antropología se define como "un todo complejo que vincula a la totalidad de manifestaciones que expresan la vida de un grupo humano" (p. 15). Asimismo, la cultura es un conjunto de hilos que forman un tejido en que se entrelazan toda clase de relaciones semánticas y sintagmáticas, pero también sociales y de intercambio de contenidos culturales a través del cual podemos hacer el ejercicio exegético de la ontología del ser.

Por otra parte, la cultura y sociedad están unidas; pues, tal como afirman Martínez et al. (2016): "La cultura sirve de integrador, articulador y cohesionador social, como catalizador de valores, los principios axiológicos de la sociedad en el ejercicio de la sana convivencia, la tolerancia, respeto mutuo y la comunicación recíproca a partir de la sociedad" (p. 18). Asimismo, desde la sociología, "la cultura es el conjunto de todas las formas de vida y expresión de una sociedad determinada. Como tal incluye costumbres, prácticas, códigos, normas y reglas de la manera de ser, vestir, religión, rituales, normas de comportamiento y sistemas de creencia" (11sociolo.blogspo, s. f.); en otras palabras, la cultura es toda la información y habilidades que posee el ser humano.

De igual forma, el aporte del UNESCO es valioso, lo hizo allá por los años 1982 desarrolla sobre el tema en su sentido más amplio:

La cultura puede considerarse actualmente como el conjunto de los rasgos distintivos, espirituales y materiales, intelectuales y afectivos que caracterizan a una sociedad o un grupo social. Ella engloba, además de las artes y las letras, los modos de vida, los derechos fundamentales al ser humano, los sistemas de valores, las tradiciones y las creencias y que la cultura da al hombre la capacidad de reflexionar sobre sí mismo. Es ella la que hace de nosotros seres específicamente humanos, racionales, críticos y éticamente comprometidos. A través de ella discernimos los valores y efectuamos opciones. A través de ella el hombre se expresa, toma conciencia de sí mismo, se reconoce como un proyecto inacabado, pone en cuestión sus propias realizaciones, busca incansablemente nuevas significaciones, y crea obras que lo trascienden. (Vives, s. f.)

El pueblo de Dios, la Iglesia, se encarna en los pueblos de la tierra, cada uno de los cuales tiene su cultura propia (Francisco, 2013, n. 115). De modo que Gaudium et spes (Pablo, 1965, n. 53) precisa su vínculo con la cultura al señalar que la vida del hombre está estrechamente ligada con la naturaleza y la cultura, resaltando dos dimensiones: la antropológica y la sociología. En la antropología, lo que hace el hombre desde su facultad de espíritu y cuerpo. En la sociológica, lo que hace en la vida social a lo largo de la historia en beneficio de su género:

Todo aquello por lo cual el hombre afina o desarrolla, en forma variadísima, las facultades de su conocimiento y el trabajo, incluso el orbe terrestre; logra hacer más humano, mediante el progreso de costumbres e instituciones, la vida social, tanto en la familia como en todo el mecanismo civil; y consigue 
expresar, comunicar y conservar profundas experiencias y ambiciones espirituales es sus obras a lo largo de los tiempos, que puede servir luego al beneficio de los demás, mejor dicho, de todo el género humano. (Pablo, 1965, n. 53)

Posteriormente, la Iglesia ha venido reflexionando sobre tema con más énfasis en relación con la imperiosa necesidad de evangelizar las culturas para inculturar el Evangelio (Francisco, 2013, n. 69). No podemos dejar de enunciar la ardua labor de los obispos en sus reuniones sobre la evangelización: en un mundo marcado por el individualismo posmoderno y globalizado que favorece un estilo de vida que debilita el desarrollo y la estabilidad de los vínculos entre personas y desnaturaliza los vínculos familiares (Francisco, 2013, n. 67). Las exhortaciones apostólicas posconciliares tocan el tema de la cultura desde la evangelización, catequesis, pastoral e inculturación. Pues, la tarea de la Iglesia es la evangelización, que la realiza asumiendo lo que hay de bueno en las culturas y renovando desde dentro (Juan Pablo II, 1990, n. 52), y en un ambiente de escucha y diálogo con las personas, realidades e historias de su cultura (Francisco, 2020, n. 66).

Evangelii nuntiandi (Pablo VI, 1975), se refiere al tema: "la cultura y las culturas del hombre en el sentido rico y amplio que tiene sus términos en el Gaudium et spes... y teniendo siempre presente las relaciones de la persona entre sí y con Dios" (n. 20). Asimismo, Catechesi tradendae (Juan Pablo II, 2004) señala que la evangelización y la catequesis está llamada a llevar la fuerza del Evangelio al corazón de la cultura y de las culturas. Para ello, procura conocer estas culturas y sus componentes esenciales, aprendiendo sus expresiones más significativas y respetando sus valores y riquezas propias (n. $\left.{ }^{\circ} 53\right)$. También Redemptoris misio (Juan Pablo II, 1990, n. 53) la recomienda comprender, apreciar, promover y evangelizar en un ambiente donde actúan los valores de la cultura.

La Iglesia en América Latina, consciente y orgullosa de su cultura autóctona, mestiza y afro, y dueña de la fuerza de una piedad popular, ha desarrollado el tema de cultura a través de las conferencias generales: Medellín, Puebla, Santo Domingo y Aparecida, documentos que ofrecen nuevos y valiosos aportes sobre la cultura. Así pues, la cultura abarca la totalidad de la vida de un pueblo, asimismo, es cultivo y expresión de todo lo humano en relación amorosa con la naturaleza y en la dimensión comunitaria de los pueblos (IV Conferencia General del Episcopado Latinoamericano, 1992, n. 228). Por otro lado, el Documento de Aparecida afirma la presencia de las "semillas del Verbo" en las culturas autóctonas, esto ha facilitado a nuestros indígenas encontrar en el Evangelio respuestas vitales a sus aspiraciones más ondas (V Conferencia General del Episcopado Latinoamericano y del Caribe, 2007, n. 4). Además, rescata su expresión de estas culturas a través del arte, la música, la literatura y, sobre todo, las tradiciones religiosas y la idiosincrasia de sus gentes, unidas por una misma historia y un mismo credo, y formando una gran sintonía en la diversidad de culturas y de lengua (Conferencia General del Episcopado Latinoamericano y del Caribe, 2007, n. ${ }^{\circ}$ 478).

Bien lo expresa el papa Francisco: que en los distintos pueblos que experimentan el don de Dios según su propia cultura la Iglesia expresa su genuina catolicidad y muestra la belleza de este rostro pluriforme (Francisco, 2013, n. 116). De modo que la noción de cultura es una valiosa herramienta para entender las diversas expresiones de la vida cristiana que se da en el Pueblo de Dios. Se trata del estilo de vida que tiene una sociedad determinada, del modo propio que poseen sus miembros de relacionarse entre sí, con las demás criaturas y con Dios (Francisco, 2013, n. 115). Asimismo, la cultura es patrimonio común de los pueblos (V Conferencia General del Episcopado Latinoamericano y del Caribe, 2007, n. 476), de 
manera especial en su sentido vivo, dinámico y participativo, que no puede excluirse a la hora de repensar la relación del ser humano con el ambiente" (Francisco, 2015, n. 143).

\section{La inculturación}

La Iglesia en su actividad misionera encuentra diversas culturas y se ve comprometida en el proceso de inculturación. Es esta una exigencia que ha marcado todo su camino histórico, pero hoy es particularmente aguda y urgente (Juan Pablo II, 1990, n. 52). Esta tarea es un proceso de transformación íntima de los auténticos valores culturales, discernidos y asumidos por la fe, son necesarios para encarnar en esa cultura el mensaje evangélico y la reflexión y praxis de la Iglesia (IV Conferencia General del Episcopado Latinoamericano, 1992, n. 229).

El término inculturación en el vocabulario del Magisterio de la Iglesia es nuevo. Este vocablo ingresa en el lenguaje del Magisterio en el Sínodo de 1974 (Scannone, 2017, p. 220) y fue empleado por el padre Arrupe en su intervención sobre la evangelización, quien ya había usado entonces el neologismo "inculturación”. Luego fue utilizado por Juan Pablo II en su encuentro con la Pontificia Comisión Bíblica, en que se refirió a la inculturación de la Palabra de Dios en las culturas bíblicas como encarnación. Más tarde, él mismo retomó, en Catechesi tradendae (Juan Pablo II, 1979), "el término inculturación, además de ser un hermoso neologismo, expresa muy bien uno de los componentes del gran misterio de la Encarnación" (n. 53); en Slavorum Apostoli (Juan Pablo II, 1985), "la inculturación es la encarnación del Evangelio en las culturas autóctonas y, al mismo tiempo, la introducción de ella en esta nueva vida de la Iglesia" (n. 21); en Redemptoris missio (Juan Pablo II, 1990), desarrolló su analogía cristológica, empleándola a la Pascua, Muerte y Resurrección (n. ${ }^{\circ}$ 52), y en Varietates legitimae (Juan Pablo II, 1994) afirma: "la inculturación significa una íntima transformación de los auténticos valores culturales por su integración en el cristianismo y el enraizamiento del cristianismo en las diversas culturas humanas" (n. 4).

El vocablo inculturación propiamente comenzó a emplearse en el ámbito de evangelización en las tierras de misión. Tal como lo define Brighenti (1997, p. 38), está compuesto por la raíz central "cultura”, rodeado por un prefijo y un sufijo. El prefijo "in" indica un movimiento de fuera hacia adentro, pero, en la perspectiva del misterio de la Encarnación, el Evangelio se encarna en la cultura para iluminar y plenificar. El sufijo "ción" indica un proceso por el misterio de Cristo, plenitud de todo ser humano.

El papa Francisco ha vuelto a poner en el centro de nuestra Iglesia este tema, muestra de ello la importancia que da a la inculturación en sus exhortaciones apostólicas Evangelii gaudium (n. 68-70) y Querida Amazonía (n. 66-90).

La Revelación y la salvación cristiana son ofrecidas a los seres humanos dentro de su trayectoria histórica y sus culturas. Es en este espacio que la Iglesia se presenta como sacramento de salvación; se ha dirigido al hombre, ha interpelado, se ha abierto a él y le ha enseñado su plan de amor. En este proceso de inculturación, el documento Santo Domingo resalta las tres grandes dimensiones de los misterios de la salvación: la Encarnación, la Pascua, Pentecostés o pneumatología (IV Conferencia General del Episcopado Latinoamericano, 1992, n. 230), mientras que Scannone (2017) añade la dimensión de piedad popular, 
dimensiones que se viven y se celebran en la Iglesia particular, intrínsecamente conectada con la Iglesia universal, la eclesiología.

El primer paso es la dimensión de Encarnación del Evangelio. La búsqueda de la inculturación a la luz de la Encarnación aparece con frecuencia en los pronunciamientos del Magisterio eclesiástico. Esta dimensión se fundamenta en la Encarnación de Jesús, Hijo de Dios, que se unió a todo hombre; trabajó con manos humanas, pensó con inteligencia humana, actuó con voluntad humana, amó con corazón humano... Se hizo verdaderamente uno de nosotros, menos en el pecado. Asimismo, también "Jesús al encarnarse, tuvo que hacerlo en el tiempo y en el espacio, asumiendo un pueblo, una historia, un lenguaje y una cultura" (França, 2004, p. 136). Así pues, la inculturación de la fe, el Evangelio y la liturgia sigue la dinámica de la Encarnación, a través de la cual el Evangelio fecunda en las diversas culturas, ya que acoge el anuncio de la salvación. Por ende, "con la inculturación la Iglesia se enriquece con nuevas expresiones y valores, manifestando y celebrando cada vez mejor el misterio de Cristo, logrando unir la fe con la vida y contribuyendo así a una catolicidad más plena, no solo geográfica, sino también cultural" (V Conferencia General del Episcopado Latinoamericano y del Caribe, 2007, n. 479).

El segundo paso de la inculturación es la dimensión pascual, "que conduce a través del sufrimiento a la purificación de los pecados, para que sean redimidos" (IV Conferencia General del Episcopado Latinoamericano, 1992, n. 230). En este sentido, en contacto con el Evangelio, las culturas pueden sufrir correcciones, purificaciones y transformaciones, a semejanza de la kenosis de Jesucristo que precedió a su resurrección victoriosa (n. 138). Por consiguiente, el proceso de inculturación implica un morir y un resucitar, que no destruye la cultura, sino que la perfecciona. Como lo afirma Piedra (2013, p. 157), la inculturación asume la Pascua, porque la salvación de Dios ha pasado por la muerte y resurrección de Jesús. Cada comunidad cuando intenta hacer vivo el mensaje de Cristo se une a su seguimiento, puesto que el Señor no está distante ni ausente del itinerario personal y comunitario, así, en la inculturación, la comunidad hoy descubre y celebra a Cristo caminando y comiendo con ella, como hizo con los discípulos de Emaús (Lc 24, 15). Es decir, la salvación pascual orienta la inculturación hacia una transformación de toda realidad. Esto implica que la inculturación no es "culturalista", sino que apunta a la liberación integral.

El tercer paso es la dimensión de Pentecostés o pneumatológica, que la fuerza del Espíritu Santo posibilita a todos entender en su propia lengua las maravillas de Dios. De modo que el hecho de Pentecostés es también evocado: todos oían la Palabra de Dios en sus respectivas lenguas (culturas). El Espíritu, a su vez, actúa en las culturas, abriéndolas a los valores evangélicos (França, 2004, p. 138). Así la acción del Paráclito es el agente principal que mueve al pueblo fiel que continúe con la evangelización. El Espíritu Santo, además, infunde la fuerza para anunciar la novedad del Evangelio con audacia (parresía), en voz alta y en todo tiempo y lugar, incluso a contracorriente (Francisco, 2013, n. 259). De ese modo, el Espíritu Santo fecunda a la cultura con la fuerza transformadora del Evangelio. Esta acción del Espíritu Santo es la que embellece a la Iglesia, mostrándole nuevos aspectos de la Revelación y regalándole un nuevo rostro. De esta forma, esta acción se trata, en definitiva, de permitir y alentar que el anuncio del Evangelio inagotable, comunicado con categorías propias de la cultura en que es anunciado, provoque una nueva síntesis con esa cultura (Francisco, 2020, n. 68). En consecuencia, una evangelización con espíritu es una evangelización con Espíritu Santo, ya que Él es el alma de la Iglesia evangelizadora. Para tal efecto, el papa Francisco invoca al Espíritu Santo; le ruega que venga a renovar, a sacudir, a impulsar a la Iglesia en una audaz salida fuera de sí para evangelizar a todos los pueblos (Francisco, 2013, n. 261). 
El cuarto paso es la dimensión de piedad popular. Esta dimensión es una manera legítima de vivir la fe, un modo de sentir parte de la Iglesia; como afirma Scannone (2017, pp. 219-220), es una forma de ser misionero; gracias al Espíritu Santo, intrínsecamente conectado con la eclesiología del pueblo fiel, su misión evangelizadora a la vez es lugar teológico al que debemos prestar atención (Francisco, 2013, n. 126). El papa Francisco indica que la piedad popular tiene mucho que enseñarnos, y para quien sabe leer la realidad, es un lugar teológico al que se debe tomar atención a la hora de evangelizar. Pues toda la vida y convivencia cristiana, en cuanto ella acoge a su modo el Evangelio entero, y lo encarna en expresiones de oración, de fraternidad, de justicia, de lucha y de fiesta (Francisco, 2013, n. 237). Al respecto, Scannone afirma: lugar teológico porque es fuente declarativa de la revelación en su recepción inculturada en una cultura determinada, y, por consiguiente, lugar de genuina teología inculturada, aunque -por ser teología- de validez universal. Y que puede servir de inspiración universal para distintas teologías inculturadas en otras culturas (p. 63). Él mismo aclara, "es lugar teológico en el sentido estricto, es decir, fuente de conocimiento de la revelación para la teología, pero no un lugar constitutivo como la Escritura o la tradición, sino declarativo". Por otra parte, la piedad popular es lugar hermenéutico de una teología inculturada, es decir, como lugar de reflexión, interpretación y conocimiento crítico del mensaje cristiano, porque es lugar privilegiado de su vivencia, de su práctica y de conocimiento sapiencial. Y así tratará de responder al legítimo deseo de inculturación de la teología. Por ello, sintetiza que la piedad popular no solo es fuente de conocimiento de la fe, sino de una fe inculturada, aunque sin menoscabo de su valor transcultural y universal.

La tarea de inculturación de la fe, el Evangelio y la liturgia es propia de las iglesias particulares bajo la dirección de sus pastores, con la participación de todo el Pueblo de Dios (IV Conferencia General del Episcopado Latinoamericano, 1992, n. 231). Por tanto, se hace, bajo los criterios fundamentales en este proceso, en la sintonía con las exigencias objetivas de la fe y la apertura a la comunión con la Iglesia universal (Juan Pablo II, 1990, n. ${ }^{\circ}$ 54; IV Conferencia General del Episcopado Latinoamericano, 1992, n. 230), de ahí la dimensión eclesiológica de la inculturación. La Iglesia es la que celebra como escuela y casa de comunión, en que los discípulos comparten la misma fe, esperanza y amor al servicio de la misión evangelizadora. Es en ella donde se vive la diversidad de carismas, ministerios y servicios, y se abre el horizonte para el ejercicio cotidiano de la comunión, a través de la cual los dones del Espíritu Santo son puestos a disposición de los demás para que circule la caridad, de ahí el protagonismo de la Iglesia particular. Las cuatro dimensiones se viven en la iglesia particular donde están ubicadas geográficamente las culturas autóctonas y a la vez es donde se da la encarnación del Evangelio e infunde el Espíritu Santo la fuerza para anunciar su novedad con audacia (parresía), en voz alta y en todo tiempo y lugar, incluso a contracorriente. Y aquí se celebra la piedad popular, camino al encuentro con el Dios Padre. Ella es el sujeto primario de la evangelización, ya que es la manifestación concreta de la única Iglesia en un lugar del mundo, y en ella verdaderamente está y obra la Iglesia de Cristo, que es una, santa, católica y apostólica (Francisco, 2013, n. 30).

\section{La cultura quechua}

La cultura quechua es una cultura viva, poseedora de muchos conocimientos ancestrales. En la cosmovisión quechua, el ser humano es parte del universo, convive con la naturaleza armoniosa respetuosamente; tiene un sentido profundo de la familia, de la comunidad, del pueblo y de la nación (García \& Roca, 2010). 
Aclaremos la denominación cultura quechua: quechua porque es la modalidad lingüística que utilizan los habitantes, por eso se denomina cultura quechua; o cultura andina por la geografía, ya que esta cultura existe en los andes centrales del América del Sur.

No es una cultura vacía, sino rica en sus manifestaciones sociopolíticas, culturales, económicas y religiosas; viva en sus tradiciones, costumbres y en su religiosidad popular, lo cual expresa la verdadera acción misionera espontánea y dinámica del Pueblo de Dios, porque se mantiene una constante transmisión a las generaciones venideras. También se caracteriza por la diversidad de flora y fauna, los restos arqueológicos precolombinos y últimamente por su arte culinario y artesanía.

Los elementos de la cultura quechua con los cuales la Iglesia puede generar un fecundo diálogo con el Evangelio en un dinámico proceso de inculturación es la lengua vernácula, el quechua; la música, el canto, los instrumentos musicales, los colores, algunos vasos, ornamentos y todos los valores humanos y espirituales que han marcado profundamente a través de los siglos la identidad de nuestros pueblos andinos. En este trabajo, solo vamos a desarrollar la música, el canto, los instrumentos musicales, los colores, el pututo en vez de la campana y el término ágape en relación con el término quechua hurḱa desde el aspecto de la caridad, solidaridad y reciprocidad.

\section{Música, cantos e instrumentos musicales de la cultura quechua: expresión de alabanza en la liturgia}

La música y el canto en la vida cotidiana del indígena quechua es parte del aspecto sociorreligioso, lo cual observamos desde tres espacios: la persona, la creación y Dios; es una relación y vivencia en armonía entre ellos, con la creación y con Dios. El canto y la música religiosa quechua tienen una fuerza evangelizadora y catequética para transmitir el mensaje salvífico de Dios al corazón del hombre andino, en la memoria de los ayllus, llaqtas y suyos (comunidades, pueblos y nación) del ande peruano, utilizando el ritmo y la melodía andina. Nuestra cultura posee su propia tradición en la música y el canto religioso en lengua quechua. Al respecto, indica Pilco (2014), en la música quechua encontramos un conjunto de himnos y villancicos en quechua, a diferencia de los conocidos cantos en latín y español.

En el repertorio de la música religiosa quechua, se maneja más el ritmo harawi. Es un género musical que está compuesto de himnos y poesías. En tiempos del imperio tawantinsuyo estos fueron dedicados a Inka, Inti, Killa, Chaska, Qoya y Nusta, a los Apus tutelares. Según el cantautor Montoya (2013), el harawi es también una forma lírica de expresión que viene de dos vertientes: una sagrada o sacra y la otra dedicada exclusivamente a la mujer, a la ñusta, a la madre. El harawi sagrado o sacro fue hecho para los dioses Inkas, ya en la Colonia fueron utilizados por los misioneros para Tayta Dios, Mamacha María; con el tiempo, este repertorio ha ingresado en proceso de influencia recíproca entre la liturgia católica y la cultura quechua. Toda esta riqueza cultural por mucho tiempo fue conservada en la tradición oral y una gran parte perdura hasta nuestros días.

Por otra parte, las letras del canto y la música quechua son poesías e himnos inspirados en la Sagrada Escritura, en la patrística y la eucología, que llevan al compromiso evangélico en medio de la sociedad andina. Estos himnos son interpretados en las misas, procesiones y veladas, los cuales impresionan cuando son escuchados en lengua quechua, a la vez, portan la fuerza y el contenido teológico, cristológico, eclesiológico y mariano. El músico y organista Castro (2008) clasifica estos himnos de acuerdo con la temática así: 
- Himnos teológicos dedicado a Dios misericordioso.

- Himnos cristológicos dedicados a Jesucristo, narra el misterio pascual en sus diferentes advocaciones.

- Himnos marianos en sus diferentes advocaciones.

- Himnos martirologios dedicados a los diferentes santos y santas.

- Himnos eclesiológicos dedicados a la Iglesia.

- Himnos de meditación. (2008, p. 17).

Estos himnos sirvieron y siguen sirviendo para exponer la doctrina cristiana y explicar metodológicamente el misterio de salvación desde la perspectiva antropológica quecha, que jamás había escuchado un mensaje de salvación y dignificación de la persona humana y quiere llevar la fe cristiana para redimirla (Oré, 1992, p. 11). Asimismo, poseen un fondo espiritual y una calidad de formación; fomentan la participación activa de toda la asamblea, y encauzan la atención y el afecto hacia lo que se está celebrando en la liturgia.

La música de la cultura quechua siempre se acompaña de instrumentos del viento, rimados con tintineo de cencerros, percusión de tambores y toque de caracoles marinos y quenas o flautas. Los instrumentos musicales de los Inkas que hasta hoy día perduran son los bombos hechos de la piel de puma. la tinya o tambor, las trompetas de caracol marino (es decir, el pututo), la quena y el pincullo, y las flautas de pan o antaras. En efecto, Castro (2008, p. 17) afirma que, junto con los españoles, llegan también los instrumentos musicales, que en el camino de la Conquista fueron fusionándose con lo español. Los españoles trajeron instrumentos de cuerda como el arpa, el violín, la guitarra y la mandolina; instrumentos de viento como el pampapiano (melodio portátil), el armonio y el acordeón. Con el correr del tiempo, fueron articulándose estos instrumentos, de ahí que se les denominen mestizos. Estos se clasifican en:

- Aerófonos: la quena, el pampapiano, el armonio y el acordeón.

- Cordófonos: violín, charango, arpa, guitarra, mandolina y bandurria.

- Menbranófonos: tinya o tambor y bombo.

El canto, la música y los instrumentos de la cultura quechua no están vinculados a usos supersticiosos ni profanos para que sean excluidos de la acción litúrgica. Pero sí pueden emplearse de forma responsable en la celebración litúrgica, ajustándose a la dignidad de la celebración y contribuyendo efectivamente a la celebración litúrgica de los fieles.

\section{Los colores que marca el tiempo litúrgico en la cultura quechua}

En la vida cotidiana del indígena quechua, encontramos los colores litúrgicos plasmados en sus tejidos y cerámicas, algunos de ellos con otro significado. El antropólogo Bueno (2011) indica que el uso de los colores de parte del poblador andino se ve desde el lenguaje cromático y etnográfico, en tal sentido, afirma: esto les ha permitido extraordinariamente manifestar su vivir cotidiano de generación en generación mediante el arte, donde se utilizan los colores naturales y con los cuales ha logrado expresar su espíritu religioso y místico, plasmado en sus dibujos resaltados por los colores.

Los colores naturales que utiliza el poblador quechua ordinariamente son yuraq (blanco), q'omer (verde), puka (rojo), yana (negro), q’ellu (amarillo) y oqe (pardo). En la vestidura sagrada de la Iglesia, se 
emplean estos colores de esta cultura, pero algunos con significado distinto. La Iglesia puede disponer su uso en sus celebraciones litúrgicas, pero observando la orientación general del misal romano (Conferencia Episcopal de Colombia, 2007, n. 346) para no causar malas interpretaciones.

La Instrucción general del misal romano n. 346 ofrece los cinco colores que utiliza en las celebraciones litúrgicas distribuidas a lo largo del ańo litúrgico. Conviene mencionar los cinco colores: blanco, rojo, verde, morado y negro. Aldazábal (2012) nos explica el significado teológico de cada color y su uso según el tiempo litúrgico:

El blanco es el color del gozo pascual, de la luz y de la vida, expresa alegría y pureza; el rojo, significa el don del Espíritu Santo que se nos hace capaces de testimoniar la propia fe hasta derramar la sangre en el martirio, es el color de la sangre y del fuego; el verde, expresa la juventud de la Iglesia, el resurgir de una vida nueva y la esperanza, la contemplación de los bienes eternos y la esperanza de alcanzar; el morado, es signo de penitencia y austeridad y el negro, simboliza la muerte, el luto y duelo. El color rosado o rosa el domingo Gaudete (tercer de Adviento) y Laetare (cuarto de Cuaresma), es símbolo de alegría, pero de una alegría efímera. (pp. 199-120)

Las iglesias particulares o locales tienen la misión de promover la inculturación de la liturgia en las culturas autóctonas, en nuestro caso la Prelatura de Sicuani. Esta iglesia particular se ubica en la zona sur andina del Perú, exactamente en la parte del sur de la región de Cusco. Las provincias que pertenecen son Canchis, Canas, Chumbivilcas y Espinar. Se encuentra aproximadamente a $3500 \mathrm{~m} \mathrm{~s}$. n. m. y la mayoría de la población todavía es quechua hablante en las comunidades campesinas.

Para el tiempo ordinario, se puede emplear el color blanco en vez del color verde, porque para el hombre y la mujer andina ordinarios significa pasaqlla (frecuente, constante, diario). Ellos y ellas usan a diario el color blanco, pero no el verde. Ya sea en el trabajo o en la fiesta, están vestidos de blanco y negro. En la cosmovisión andina, significa fertilidad, abundancia, conversión permanente y punto de inicio de buenos propósitos. A la vez, simboliza salud y paz, pero la paz en sentido de equilibrio y armonía con los conciudadanos, con la naturaleza y con Dios. De este modo, la Iglesia se enriquece con nuevas expresiones y valores, manifestaciones y celebraciones del misterio de Cristo, logra unir la fe con la vida, y así contribuye a una catolicidad más plena, no solo geográficamente, sino también cultural (V Conferencia General del Episcopado Latinoamericano y del Caribe, 2007, n. 479).

Para el tiempo de Navidad, Pascua, las fiestas del Señor, de la Virgen y de los santos, se debe usar el color dorado (el amarillo). El color dorado en la cosmovisión andina significa fidelidad, el amor a los ayllumasis (comuneros), a la naturaleza y a Tayta Dios; este color se relaciona con la luz del sol y del fuego; también significa la lealtad, la fuerza y el oro; para el indígena del ande es un metal sagrado enviado por el tayta Inti (padre sol). Ellos lo relacionan con el culto religioso y servía para dar a conocer el rango de la deidad. Litúrgicamente, se trata de destacar también lo estético y lo noble para resaltar la solemnidad. El color dorado puede muy bien ser utilizado en las celebraciones litúrgicas de la Iglesia; este color expresa la lealtad y la fortaleza de Dios para el indígena del ande, quienes con algarabía y alegría celebran sus fiestas patronales con la confianza en que el Tayta Dios los ama y bendice.

El color rojo en la cosmovisión andina representa la sangre de los hombres y de las mujeres que dieron su vida por la justicia y la verdad. Para el hombre del ande, el paqtachay (lo justo, justicia) es aquello que 
guarda armonía con el Pacha; es decir, con el orden natural, con el cosmos; es el espacio de la vida. La verdad en el idioma quechua significa suti, cheqaq. Asimismo, el color rojo significa la sangre de los ancestros que estos dejan correr, para permitir vivir al hombre, para dar vida a todos los seres que viven y habitan en la pachamama. Por su parte, el color rojo, en la celebración litúrgica de la Iglesia, simboliza la pasión y muerte de Cristo, y la sangre derramada de los santos mártires. Se emplea en el Domingo de Ramos, el Viernes Santo, el domingo de Pentecostés y para todas las fiestas de los apóstoles, evangelistas y mártires. En efecto, recuerda el fuego del Espíritu, el fuego del amor que es capaz de llegar hasta el derramamiento de la sangre; este color no merece cambio por otro.

El color negro, después de la reforma litúrgica de la Iglesia, ha quedado discretamente relegado, aunque aún conserva su uso facultativo, en que es tradicional en las exequias y demás celebraciones de difuntos. En el mundo, posee su propia connotación, como es el respeto a lo sagrado, a la persona y la naturaleza. También representa protección, seriedad y elegancia. Es el color más utilizado junto con el blanco, colores que en las actividades cívico-religiosas engalanan. Por tal razón, proponemos que se puede retomar el uso del color negro para las celebraciones de las exequias, tiempo de adviento y cuaresma, desde el sentido de respeto a lo sagrado, en que Dios padre protege a todos con mucho amor a sus hijos e hijas que caminan juntos hacia Él que los espera.

\section{El pututu}

El pututu, o pututo, término quechua, en español conocido como caracola, es un instrumento de viento hecho de caracol marino, que se usa hasta la actualidad en las comunidades campesinas de la región de Cusco; en la zona urbana, se emplea para las procesiones, para anunciar la llegada de algún personaje importante, para llamar a la reunión comunal de los ayllu runas (los comuneros), también para dar aviso de algún suceso urgente.

Este instrumento utilizaba en tiempo de los incas, a los chaskis (recibidores), como un correo imperial. Los chaskis eran jóvenes que llevaban mensajes del inca a los pueblos del Tahuantinsuyo, recorriendo qhapaq ñan (camino real), y, antes de llegar al pueblo, anunciaban su llega al sonido de pututu.

Este instrumento se utiliza para ceremonias religiosas importantes desde el tiempo de los incas; hoy se emplea, como mencionamos, para las procesiones, para avisar la llegada del sacerdote, en la celebración de la eucaristía, en el momento de la elevación del Cuerpo y Sangre de Cristo. El que toca es un personaje respetado en la comunidad y tiene que ser casado en la Iglesia.

El pututu es un instrumento útil para la comunidad, que puede ser empleado en las celebraciones litúrgicas en vez de la campana, pues favorecería la participación activa expresando y desarrollando al mismo tiempo la unidad de todos los participantes. 


\section{El ágape, fiesta de comunión fraterna de la comunidad}

El vocablo ágape proviene del griego y significa amor y afecto; desde el lenguaje cristiano, se conoce como convite que tenían entre sí las primeras comunidades cristianas. También significa hacer beneficio para con los pobres, con los necesitados de la comunidad, solidaridad que siempre debería tenerse para con los pobres. El ágape en la percepción cristiana es un amor que se hace patente en la ayuda a los demás, con aquel prójimo que está necesitado. A la luz de Jesús, ágape, el amor, "se subraya el amor con que se ama a la otra persona atendiendo a su necesidad o deseo, y buscando su bien aun cuando apenas se recibe de ella nada gráficamente" (Pagola, 2018, p. 29).

La exhortación apostólica Deus caritas est (Benedicto XVI, 2007), señala que hay diferencia y unidad entre eros y ágape. El eros como término para expresar amor mundano y el ágape como denominación del amor fundante en la fe y plasmado por ella (n. 7).

El eros ascendente es para buscar cada vez más la felicidad del otro, se preocupa de él, se entrega y desea ser para el otro. Por otro lado, el ágape es el amor descendente, oblativo, un don que se da gratuitamente a quien recibe, que no busca su propio interés o satisfacción, su seguridad o bienestar, sino que solo piensa en hacer el bien, acoger, regalar lo mejor que tiene, ofrecer amistad, ayudar a vivir. El eros y el ágape nunca llegan a separarse completamente. Por contrario, ambos encuentran, aunque en diversa medida, la justa unidad en la única realidad del amor.

Para el cristiano de la cultura quechua de esta época, aún no es familiar el vocablo ágape ni el eros, particularmente para los cristianos que viven en las zonas rurales. Puede ser que en algún momento escucharon el término, pero en relación con el banquete o comida en abundancia. Por tal motivo, recurrimos al término quechua la hurk'a que nos puede ayudar a transmitir el mensaje del Evangelio, amor a Dios y al prójimo, el don de dar por gratitud a quien necesita ayuda, acogida sin esperar alguna retribución, por existir una similitud entre el ágape y hurk'a en su significado. La hurk'a es el tejido social de la cultura quechua, a través del cual toma forma la caridad, solidaridad y reciprocidad, que se difunde y retroalimenta en los ayllus. Este sistema es parte de la construcción de una red de solidaridad entre ellos, con los peregrinos y hoy con los migrantes que llegan de otras latitudes a estas tierras en busca de corazones solidarios y manos acogedoras que les permita vivir con esperanza y dignidad.

La hurk'a en el mundo quechua es la acción que consta de tres pasos: el acto de dar, que se hace en favor de la persona, familia o comunidad por amor, por la necesidad que pasa; el acto de recibir, el que recibe la hurk'a está en la obligación de administrar honestamente, no puede vender, mucho menos desperdiciar, y el acto de redistribuir, el que ha recibido está en la obligación de redistribuir en conciencia a todos por equidad, que ocurre cuando se le ha dado a una familia, la comunidad y al caguyoq. Para entender mejor este concepto, menciono tres ejemplos. Cuando una persona cae en desgracia y ha perdido todos sus bienes y alimentos, recurre a la hurk'a entre sus familiares, vecinos y amigos, para sobrevivir y empezar de nuevo. La otra ocurre cuando una familia de recién casados o convivientes quieren construir su casa, entonces acuden a la hurk'a ofreciendo hojas de coca y un vaso de aqha (chicha) en su entorno social, medios que se utilizan para tener la ayuda de familiares, ahijados, vecinos y comunidad. Con la coca y la aqha, inicia el diálogo de cualquier solicitud o arreglo de los problemas familiares, del ayllu y del suyo. El tercer acto está relacionado con la fiesta patronal: la persona o familia que cogió cargo o mayordomía de la fiesta 
patronal también recurre a la hurk'a. Estas personas están en la obligación moral de redistribuir todo lo que recibieron a todos los asistentes de la fiesta. No solo en dar alimentos en abundancia, sino también jolgorio, alegría, y así renovar la fuerza para continuar la vida productiva de la gente y de la comunidad.

En la vivencia religiosa de la cultura quechua, la hurk'a está presente, práctica a la que recurren los corguyoq (encargado o responsable de la fiesta) o los mayordomos. Así pues, la burk'a es un proceso que legitima la forma intracomunal de redistribución prehispánica, pero en un contexto religioso católico. Este acto se estableció en una realidad religiosa y católica con símbolos católicos para acomodar o hacer fluir los principios prehispánicos. En el contexto religioso, hay tres formas de reciprocidad. Jesucristo, la Virgen María y los Santos que son los dadores. Los carguyoq o mayordomos son los receptores momentáneos de los bienes, y los participantes de la fiesta son destinatarios de la redistribución. Ellos están en la obligación de redistribuir en bienes y servicios consumibles, de esta manera devuelven productividad, fertilidad, fecundidad y vitalidad a todos los participantes de la fiesta, en honor del Tayta Dios, a la Mamacha María, de los santos o santas de la devoción.

\section{Conclusiones}

Así pues, la inculturación caracteriza tanto el proceso como origen y de la evangelización, que está llamada a llevar la fuerza del Evangelio al corazón de la cultura y las culturas. Por otra parte, la inculturación implica que la predicación del Evangelio del Reino de Dios dirigida a y en un contexto particular en el tiempo y en el espacio, en este caso la cultura andina, tiene que ver con la proclamación de la revelación histórica de Dios en Jesucristo, con su acogida en la fe y con su crecimiento en la vida eclesial y personal de los cristianos (Francisco, 2015, p. 592).

Para que el proceso de inculturación litúrgica tenga éxito y futuro, el ordinario del lugar tiene que estar involucrado con los agentes de pastoral. Asimismo, para avanzar con firmeza y confianza en esta tarea, se demanda la comunión con las Iglesias de la misma provincia eclesiástica, con la Conferencia Episcopal y con la Congregación para el Culto Divino y la Disciplina de los Sacramentos, pues no somos dueños de la liturgia sino sus servidores. Sin embargo, considerar a la Iglesia particular en este proceso, porque ella hace la inculturación, pero siempre en comunión con quien preside la Iglesia universal y sus colaboradores.

Para una buena inculturación litúrgica en los pueblos autóctonas, indígenas, no basta la buena voluntad y el cariño del misionero por ello. Se requieren dos aspectos: primero, el requisito indispensable, conocer a fondo la historia, la teología y la pastoral de la liturgia; y segundo, la historia, la antropología y la sociología de las culturas autóctonas, indígenas. Esto demanda una labor interdisciplinaria: la participación de la misma comunidad, de los catequistas, de los jóvenes, de los ancianos y de los agentes pastorales; también la participación de los profesionales: los antropólogos y sociólogos. Asimismo, requiere tiempo, paciencia, constancia y recursos económicos.

La cultura quechua es una cultura rica en sus manifestaciones sociopolíticas, culturales y económicas; viva en su tradición, en sus costumbres y en la religiosidad popular, y dinámica en su proceso de transmisión a las futuras generaciones. También es rica en la fe, porque las "semilla del Verbo" presente ha facilitado 
encontrase con Cristo salvador; por eso, gran parte de ellos han recibido el bautismo y expresan su fe y su solidaridad fraterna de múltiples maneras. No se puede ignorar la fe de esta cultura; más allá de las limitaciones que tenga, ella tiene mucho más recursos que una mera suma de creyentes frente a los desafíos del secularismo, el consumismo y la corrupción descarada de sus autoridades.

\section{Referencias}

Aldazábal, J. (2000). Gestos y símbolos. Barcelona: Centro de Pastoral Litúrgica.

Aldazábal, J. (2012). Ordenación general del Misal Romano. Barcelona: Centre de Pastoral Litúrgica.

Augé, M. (1997). Liturgia historia celebración teología espiritualidad. Barcelona: Centre de Pastoral Litúrgica.

Augustin, G. \& Koch, K. (2013). La liturgia como centro de la vida cristiana. Santander: Sal Terrae.

Basurko, X. (2006). Historia de la liturgia. Barcelona: Centre de Pastoral Litúrgica.

Benedicto XVI. (2007). Deus caritas est. Lima: Paulinas.

Bonet, S. \& Pinedo, H. (2014, 22 de agosto). La hurk'a ¿ayni o mink'a? Recuperado de http://relatoscusco.blogspot. com/2014/08/hurka-ayni-minka-reciprocidad.html

Borobio, D. (2003). Celebrar para vivir. Salamanca: Sígueme.

Brighenti, A. (1997). Por una evangelización inculturada. Bogotá: Paulinas.

Bueno, O. (2011)._Lenguajesimbólic. Recuperado de https://casadelcorregidor.pe/colaboraciones/_biblio_Bueno-R.php

Cardenal, P. (2004). Cultura y fe Iglesia y diversidad cultural. Valencia: Edicep.

Castro Pinto, R. (2008). Willka taki I y II. Lima: Unión Latina.

Catecismo de la Iglesia católica. (1993). Lima: Paulinas.

Causse, J.-D. (2006). El don del agapé. Santander: Sal Terrae.

Conferencia Episcopal de Colombia. (2007). Instrucción general del misal romano. https://www.vatican.va/roman_ curia/congregations/ccdds/documents/rc_con_ccdds_doc_20030317_ordinamento-messale_sp.html

El Antropólogo Principiante. (s. f.). La antropología. Recuperado de https://antropologoprincipiante.com/antropologia/

Fernández de Rota, J. A. (2009). El concepto de cultura en la antropología contemporánea. Consello da Cultura Galega. Recuperado de https://www.academia.edu/download/34619581/texto_fernandez_de_rota.pdf

Francisco. (2013). Evangelii gaudium. Lima: Paulinas.

Francisco. (2015). Laudato si'. Bogotá: San Pablo.

Francisco. (2020). Querida Amazonía. Bogotá: San Pablo.

Goñi Beásoain de Paulorena, J. A. (2009). El sacerdocio de Cristo y su ejercicio en la liturgia. Phase, 49(289), 65-74.

Juan Pablo II. (1979). Catechesi tradendae. Lima: Paulinas. 
Juan Pablo II. (1985). Slavorum Apostoli. Lima: Paulinas.

Juan Pablo II. (1990). Redemptoris missio. Lima: Paulinas.

Juan Pablo II. (2004). Catechesi tradendae. Lima: Paulinas.

Kasper, W. (2015). La Liturgia de La Iglesia. Cantabria: Editorial Sal Terrae.

Martínez Heredia, K., Bermúdez, E., Luquetta Cediel, D. J. \& Beltrán Romero, C. (2016). El sentido de la cultura en el desarrollo de los pueblos. Revista Kavilando, 8(1), 13-22. https://www.ssoar.info/ssoar/handle/ document/63519

Miranda, M. de F. (2004). La inculturación de la fe: un abordaje teológico. Bogotá: Conferencia Episcopal Latinoamericano.

Molina Vélez, G. (2015). La Sacrosanctum Concilium: planteamientos, logros y desafíos. Cuestiones Teológicas, 42(97), 71-99. Recuperado de http://www.scielo.org.co/scielo.php?script=sci_abstract\&pid=S0120$131 \mathrm{X} 2015000100003$

Montoya, R. (2013). Encanto y celebración del wayno. Lima: Dirección Regional de Cultura Cusco.

Oré, L. J. de. (1992). Symbolo catholico indiano. Lima: Australis.

Pablo, Obispo. Sacrosanctum concilium. Dic 4 de 1963. Recuperado de https://www.vatican.va/archive/hist_councils/ ii_vatican_council/documents/vat-ii_const_19631204_sacrosanctum-concilium_sp.html

Pablo, Obispo. Gaudium et spes. Dic 7 de 1965. http://www.vatican.va/archive/hist_councils/ii_vatican_council/ documents/vat-ii_const_19651207_gaudium-et-spes_sp.html

Pablo, Obispo. (2004). Constitutio de Sacra Liturgia. Cuadernos Phase, 141, 35-105.

Pablo VI. Vaticano II. Evangelii nuntiandi. Dic 8 de 1975. Recuperado de http:/www.vatican.va/content/paul-vi/ es/apost_exhortations/documents/hf_p-vi_exh_19751208_evangelii-nuntiandi.html

Pagola, J. A. (2018). Dejar entrar en casa a Jesús. Madrid: PPC.

Pérez, A. (2004). La Enciclopedia (vol. 1). Madrid: Salvat.

Piedra, J. (2013). La misión andina. Lima: Universidad del Pacífico.

Pío XII. Mediator Dei. Nov 20 1947. Recuperado de http://www.vatican.va/content/pius-xii/es/encyclicals/documents/ hf_p-xii_enc_20111947_mediator-dei.html

Pilco, E. (2014). Himnos religiosos en quechua. Cusco: Dirección Desconcentrado de Cultura Cusco.

Real Academia Española. (2014). Diccionario de la lengua española (tomo I). Madrid: EPASA

Sartore, D. y Triacca, A. (1984). Nuevo diccionario de liturgia. Madrid: Paulinas.

Scannone, J. C. (2017). La teología del pueblo. Vizcaya: Sal Terrae.

Spadaro, A. \& Galli, C. M. (2016). La reforma y las reformas en la Iglesia. Vizcaya: Sal Terrae.

Vives Azancot, P. A. (s. f.). Concepto de cultura para la gestión. En Manual atalaya. Recuperado de http:// atalayagestioncultural.es/documentacion/concepto-cultura-gestion 
La inculturación de la liturgia en la cultura quechua

11 sociolo.blogspo. (s. f.). Sociedad y cultura [Entrada blog]. Recuperado de http://11sociolo.blogspot.com/p/31sociedad-y-cultura.html

IV Conferencia General del Episcopado Latinoamericano. Santo Domingo Conclusiones. Lima: Conferencia Episcopal Peruano.

V Conferencia General del Episcopado Latinoamericano y del Caribe. (2007). Aparecida Documento final. Lima: Paulinas. 